\title{
Effect of Solution Carbon and Nitrogen on the Microstructural Size and Crystallography of Lath Martensite in Fe-N and Fe-C Alloys
}

\author{
Shigekazu Morito ${ }^{1, * 1}$, Yuki Iwami ${ }^{2, * 2}$, Tamotsu Koyano ${ }^{3}$ and Takuya Ohba ${ }^{1}$ \\ ${ }^{1}$ Department of Materials Science, Shimane University, Matsue 690-8504, Japan \\ ${ }^{2}$ Department of Materials Analysis, Shimane University, Matsue 690-8504, Japan \\ ${ }^{3}$ Cryogenics Division, Research Facility Center, University of Tsukuba, Tsukuba 305-8577, Japan
}

\begin{abstract}
Microstructures of lath martensite that contains bec or bet martensite crystals in Fe-C alloys are known to depend on the carbon content of the alloys. The effect of nitrogen content on microstructure, however, has not yet been elucidated. This study elucidates the effects of carbon and nitrogen content on microstructures via local crystallographic analysis. We found that the packet sizes are similar when the nitrogen content in the alloys are the same as the carbon content, with the packet size decreasing with increasing carbon and nitrogen content. The block and subblock thicknesses in low nitrogen lath martensite are smaller than those in low carbon lath martensite, whereas those in medium and high carbon and nitrogen lath martensites are similar. Martensite lath thickness and dislocation density in the Fe- $\mathrm{N}$ alloy laths are lower than those in the Fe$\mathrm{C}$ alloys laths, and the distribution of misorientation angles between adjacent the blocks and sub-blocks in Fe- $\mathrm{N}$ alloys is similar to that in Fe- $\mathrm{C}$ alloys. [doi:10.2320/matertrans.MB201503]
\end{abstract}

(Received August 11, 2015; Accepted September 28, 2015; Published November 13, 2015)

Keywords: lath martensite, iron-nitrogen, iron-carbon, morphology, dislocation density, crystallography

\section{Introduction}

Lath martensite with interstitial atoms constructed by bcc or bct martensite crystals is an important microstructure that contributes to high strength and toughness in materials required for steels used in structures and tools such as axles and cutting blades. Fine and hierarchical microstructure is an important feature of lath martensite ${ }^{1)}$ because the toughness of lath martensite is attributed to its complex microstructures. $^{2)}$

Crystallography and morphology of lath martensite in $\mathrm{Fe}-$ $\mathrm{C}$ alloys have been studied by many researchers using transmission electron microscopy (TEM), X-ray diffraction and other methods. Recently, their morphologies were related to their crystallographic properties using a local crystal orientation analysis method, i.e. scanning electron microscopy/electron backscatter diffraction analysis (SEM/EBSD) method. ${ }^{3)}$ Using these methods, the microstructures of lath martensite in $\mathrm{Fe}-\mathrm{C}$ alloys can be identified and characterised quantitatively. ${ }^{4}$

Lath martensite appears in $\mathrm{Fe}-\mathrm{C}$ as well as $\mathrm{Fe}-\mathrm{N}$ alloys. The transformation kinetics and crystallographic features such as martensitic transformation start temperature ${ }^{5)}$ and lattice parameters ${ }^{6)}$ are similar in both alloys. Ngo et al. ${ }^{7)}$ reported that there is no difference in their morphologies. However, microstructural information on lath martensite in $\mathrm{Fe}-\mathrm{N}$ alloys, such as dislocation density and block thickness, has not yet been obtained. This information is important for understanding the transformation mechanism and development process of lath martensite because hardness, dislocation motion and stacking fault energy of austenite in $\mathrm{Fe}-\mathrm{C}$ and $\mathrm{Fe}-\mathrm{N}$ alloys are different. ${ }^{8)}$ Furthermore, from the standpoint of industrial applications, such information is useful for the microstructure control of lath martensite in nitriding steels.

\footnotetext{
${ }^{* 1}$ Corresponding author, E-mail: mosh@ riko.shimane-u.ac.jp

${ }^{* 2}$ Graduate Student, Shimane University. Present address: Kimura Chuzosho Co., Ltd., Omaezaki 437-1615, Japan
}

This study is aimed to elucidate the effect of solution nitrogen on the crystallographic features and microstructural sizes of lath martensite in $\mathrm{Fe}-\mathrm{N}$ binary alloys. The results were compared with those of $\mathrm{Fe}-\mathrm{C}$ alloys and the differences between the solution carbon and nitrogen were discussed.

\section{Experimental Procedure}

Initial $\mathrm{Fe}-\mathrm{N}$ alloy specimens were $10 \times 10 \times 0.3 \mathrm{~mm}$ sheets of $99.9 \%$ pure iron. The specimens were prepared using gas nitriding method in $\mathrm{NH}_{3}+\mathrm{H}_{2}$ atmosphere at $1203 \mathrm{~K}$ for $14.4 \mathrm{ks}$ after decarbonisation in dry hydrogen atmosphere at $1273 \mathrm{~K}$ for $3.6 \mathrm{ks}$. After nitriding, the specimens were quenched in water to obtain a fully lath martensite. Chemical compositions of the specimens were $\mathrm{Fe}-0.87 \mathrm{~N}, 0.94 \mathrm{~N}, 1.43 \mathrm{~N}, 1.65 \mathrm{~N}, 2.00 \mathrm{~N}, 2.60 \mathrm{~N}$ and $2.70 \mathrm{~N}$ (at\%), henceforth referred to as Fe-0.22N, $0.24 \mathrm{~N}, 0.36 \mathrm{~N}$, $0.42 \mathrm{~N}, 0.51 \mathrm{~N}, 0.67 \mathrm{~N}$ and $0.69 \mathrm{~N}$ (mass\%), respectively.

Bulk $\mathrm{Fe}-\mathrm{C}$ alloy specimens were used for comparison of the microstructures. Chemical compositions of the specimens were $\mathrm{Fe}-0.01 \mathrm{C}-1.50 \mathrm{Mn}-0.05 \mathrm{Ti}-0.03 \mathrm{Al}-0.01 \mathrm{~B}$ (hereafter $\mathrm{Fe}-0.01 \mathrm{C}-1.50 \mathrm{Mn}$ ), $0.83 \mathrm{C}, 1.74 \mathrm{C}$ and $2.77 \mathrm{C}$ (at\%), henceforth referred to as $\mathrm{Fe}-0.0026 \mathrm{C}-1.48 \mathrm{Mn}, 0.18 \mathrm{C}, 0.38 \mathrm{C}$ and $0.61 \mathrm{C}$ (mass\%), respectively. All specimens were austenitised at 1373,1473 or $1573 \mathrm{~K}$ and quenched in iced brine to obtain a fully lath martensite structure.

Optical micrographs were taken from the inside of the specimens after etching by $3 \%$ nital liquid $\left(3 \mathrm{vol} \% \mathrm{HNO}_{3}+\right.$ $\left.97 \mathrm{vol} \% \mathrm{C}_{2} \mathrm{H}_{5} \mathrm{OH}\right)$. Using the micrographs, the prior austenite grain (PAG) and packet sizes were measured by the line intercept method. The PAG size $d_{\gamma}$ is defined as:

$$
d_{\gamma}=1.128 l
$$

where $l$ is the average intercept length between the PAG or packet boundaries, and the coefficient is calculated from spherical approximation of the PAG and packet.

SEM/EBSD measurements were performed using a Hitachi S-3100H and a JEOL JSM-6500F operated at 
$25 \mathrm{kV}$ with scan steps of $0.1 \sim 0.5 \mu \mathrm{m}$, and the patterns were indexed as the alpha-iron phase (bcc metal). Prior to measurements, the specimens were electropolished by $\mathrm{CH}_{3} \mathrm{COOH} 950 \mathrm{ml}+\mathrm{HClO}_{4} 50 \mathrm{ml}$ liquid.

In this study, Kurdjumov-Sachs (KS) orientation relationships between austenite and martensite $\left(\{111\} \gamma / /\{011\} \alpha^{\prime}\right.$ and $\left.\langle\overline{1} 01\rangle \gamma / /\langle\overline{1} \overline{1} 1\rangle \alpha^{\prime}\right)$ were used for crystallographic analyses. ${ }^{4)}$ To identify the packets using SEM/EBSD measurements, the packets were redefined as a group of laths with the same close-packed plane parallel relationship with the austenite. Furthermore, a block can be defined as a group of laths with the same lattice correspondence as in a packet, e.g. a block is a group of laths with similar crystal orientations. In low carbon lath martensite, each block consists of laths with two KS variant groups that are misoriented by small angles of about $10^{\circ}$. A sub-block can also be defined as a group of laths with the same KS variant.

The apparent block and sub-block thicknesses, $t_{\mathrm{b}}$ ', were measured using EBSD colour images and converted to the true thicknesses (perpendicular distance), $t_{\mathrm{b}}$, depending on the habit plane orientation of laths forming the block and subblock:

$$
t_{\mathrm{b}}=t_{\mathrm{b}}{ }^{\prime} \sin \theta
$$

where $\theta$ is the angle between the normal of the lath habit plane $\left(\sim(011) \alpha^{\prime} / /(111) \gamma\right)$ and the normal direction of the specimen surface. SEM/EBSD step size was fixed as $0.2 \mu \mathrm{m}$ for size measurements. More than thirty and twenty blocks were performed for the $\mathrm{Fe}-\mathrm{C}$ and $\mathrm{Fe}-\mathrm{N}$ alloys, respectively.

TEM observations using a JEOL JEM-2010 and a TOPCOM 002B operated at $200 \mathrm{kV}$ were also performed to measure lath thicknesses and dislocation densities. The TEM specimens were prepared with the twin-jet-polishing method using $\mathrm{HClO}_{4} \quad 50 \mathrm{ml}+\mathrm{C}_{2} \mathrm{H}_{5} \mathrm{OH} \quad 700 \mathrm{ml}+\mathrm{CH}_{3}\left(\mathrm{CH}_{2}\right)_{3} \mathrm{O}$ $\left(\mathrm{CH}_{2}\right)_{2} \mathrm{OH} 100 \mathrm{ml}+\mathrm{H}_{2} \mathrm{O} 137 \mathrm{ml}$ liquid. To observe the lath boundaries using TEM, laths were observed in parallel along their habit planes. Dislocation densities $(\rho)$ were measured on the TEM micrograph by the line intercept method $^{9)}$ and by applying the following equation:

$$
\rho=2 N / L t
$$

where $N$ is the number of intersections with dislocations made by randomly drawn lines of length $L$ on the TEM image, and $t$ is the foil thickness. Observations were made at two (medium nitrogen specimen) or three (the other specimens) chosen areas. The dislocations were observed in a two-beam condition for $002 \alpha^{\prime}$ or $004 \alpha^{\prime}$, which were the dislocation visible conditions, i.e. $\boldsymbol{g} \cdot \boldsymbol{b} \neq 0$. The local thickness of the thin foil specimen $(t)$ was determined by the convergent-beam electron diffraction method. ${ }^{10)}$

\section{Results and Discussion}

Optical micrographs of Fe- $0.87,1.65$ and 2.70 at $\% \mathrm{~N}$ alloy specimens are shown in Figs. 1(a), (b) and (c), respectively. All specimens contained the traditional microstructure of lath martensite, i.e. blocks, packets and PAG. Low nitrogen lath martensite (Fig. 1(a)) contained plate-like blocks with length that was equal to the packet diameter. Medium nitrogen lath
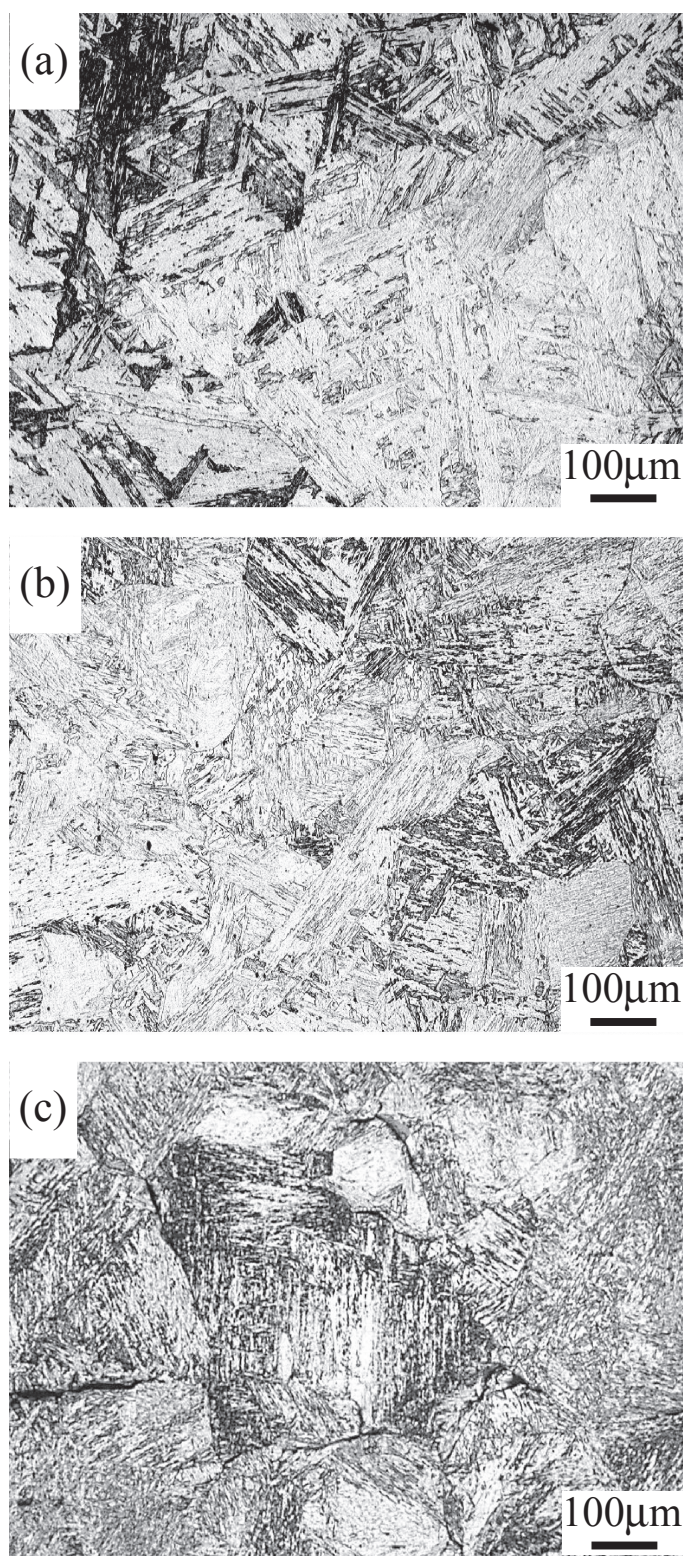

Fig. 1 Optical micrographs of the specimens in (a) Fe-0.87, (b) 1.65 and (c) 2.70 at $\% \mathrm{~N}$ alloys.

martensite in Fig. 1(b) is also constructed by blocks and packets; however, the block length is smaller than that in the low nitrogen lath martensite. Quantitatively measuring the size of blocks in high nitrogen lath martensite is difficult. These morphologies are similar to those observed in the $\mathrm{Fe}-\mathrm{C}$ alloys. ${ }^{11)}$

To measure their microstructural sizes, the microstructures were observed using SEM/EBSD. Figures 2(a), (b) and (c) are orientation image maps of grain boundaries in a packet in $\mathrm{Fe}-0.87,1.65$ and 2.70 at $\% \mathrm{~N}$ alloys, respectively. The colours in these maps indicate that the crystal orientations are parallel to the normal direction and correspond to a standard stereographic triangle in Fig. 2(d). The black and grey lines correspond to the high and low angle grain boundaries, respectively, with a threshold of $15^{\circ}$. These maps clearly show that blocks and sub-blocks become finer with increasing nitrogen content. This tendency is similar to that observed for the $\mathrm{Fe}-\mathrm{C}$ lath martensite. 

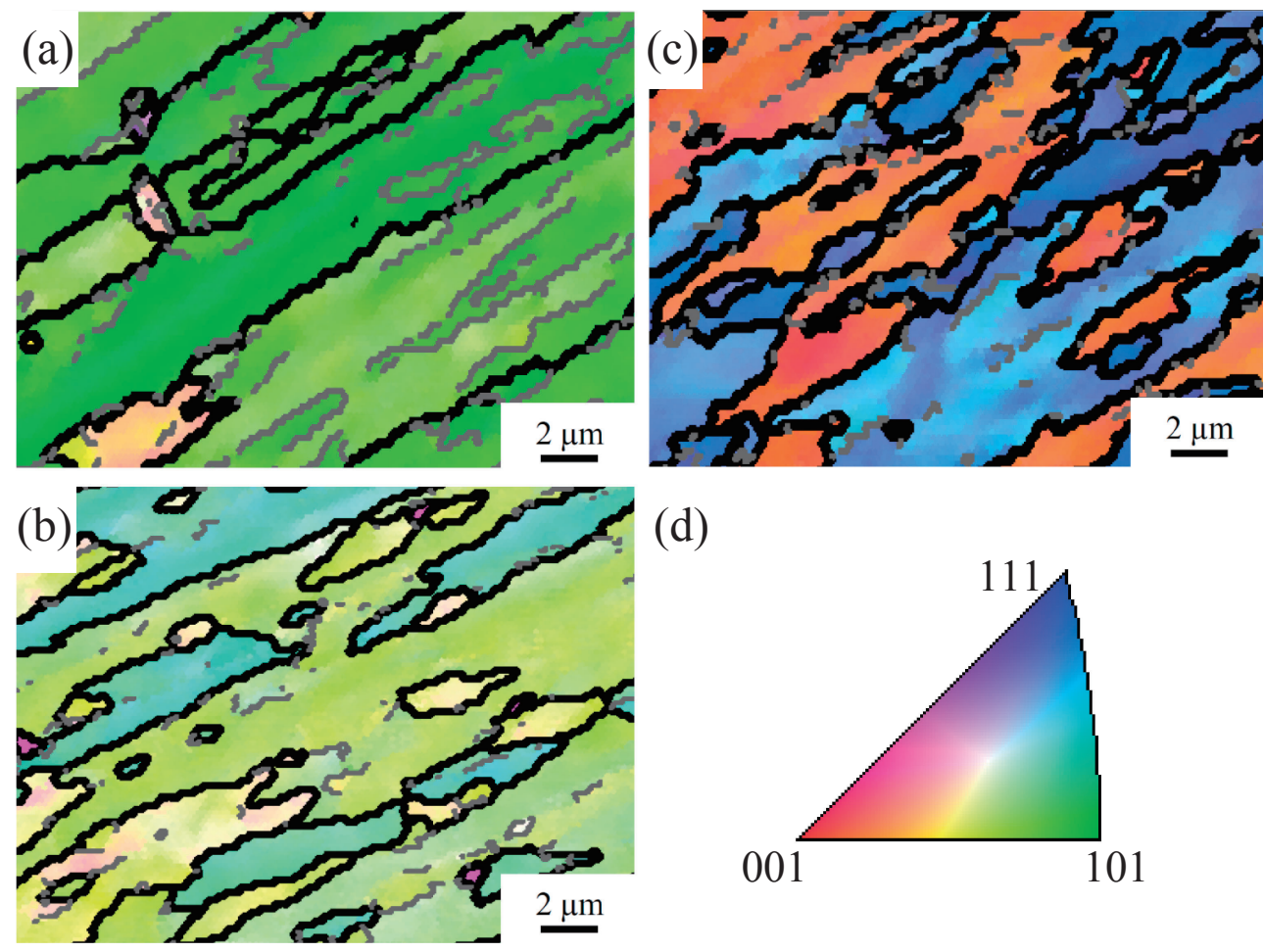

(d)

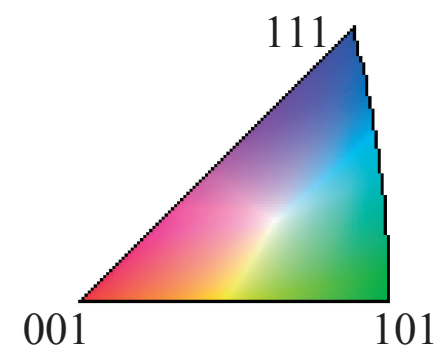

Fig. 2 Orientation image maps of grain boundaries in a packet for (a) Fe-0.87, (b) 1.65 and (c) 2.70 at\% N alloys, and (d) the coloured standard stereographic triangle for these maps. Colours in Figs. 2(a), (b) and (c) indicate crystal orientations parallel to normal direction, as shown in Fig. 2(d). Black and grey lines correspond to high and low angle grain boundaries, respectively.

Lath thicknesses and dislocation densities were measured with TEM as shown in Figs. 3(a), (b) and (c) for Fe-0.87, 1.65 and 2.70 at $\% \mathrm{~N}$ alloys, respectively. The laths in the specimens display flat surfaces and similar thicknesses. The dislocation morphology in the laths is predominantly straight. Retained austenite films between the martensite laths were also observed similar to the case of $\mathrm{Fe}-\mathrm{C}$ lath martensite.

Macroscopic structural data, i.e. the average PAG, packet, block and sub-block (or single variant region) sizes, are shown in Table 1. Table 2 shows the average martensite lath thickness and dislocation density in $\mathrm{Fe}-\mathrm{N}$ alloys. The average microstructural sizes in $\mathrm{Fe}-\mathrm{C}$ martensite measured using the same methods are listed in Table 3. To compare packet, block and sub-block sizes in all specimens, it is necessary to relate them to the PAG size, which is difficult to control. Thus, the packet size and block and sub-block thicknesses were divided by the PAG size, because these size and thicknesses exhibit a proportional relationship with the PAG size. ${ }^{12,13)}$ Figures 4(a), (b) and (c) show the relationships of the microstructural sizes with the nitrogen and carbon content. The packet size/PAG size ratio in $\mathrm{Fe}-\mathrm{N}$ alloys decreases with increasing nitrogen content and is similar to that in $\mathrm{Fe}-\mathrm{C}$ alloys. On the other hand, the block and sub-block thickness/ PAG size ratios are not sensitive to the nitrogen content.

The distribution of block boundary misorientation angles in a packet depends on the carbon composition of the solution, as shown in Fig. 5(a). In a packet, four types of block boundary angles around the common $[011] \alpha^{\prime}$ direction are found: $7^{\circ}, 52^{\circ}, 60^{\circ}$ and $68^{\circ}{ }^{4)}$ In the figure, low angle boundaries correspond to sub-block boundaries. The misorientation angles are slightly different from the theoretical angle values calculated from the KS orientation relationship between austenite and martensite; this is because the experimental orientation relationship is not exactly the same as the KS orientation relationship. ${ }^{14)}$ In the Fe-0.01 at\% $\mathrm{C}-1.50$ at\% $\mathrm{Mn}$ alloy, blocks contain sub-blocks with no specific relationship to the other blocks. In this case, the $[011] \alpha^{\prime} / 52^{\circ}:[011] \alpha^{\prime} / 60^{\circ}:[011] \alpha^{\prime} / 68^{\circ}$ ratio is $1: 2: 1$. As the carbon content increases, the fraction of low angle boundaries decreases and that of the $[011] \alpha^{\prime} / 68^{\circ}$ boundaries increases. Furthermore, in the $\mathrm{Fe}-2.78$ at $\% \mathrm{C}$ alloy, misorientation angle of $[011] \alpha^{\prime} / 68^{\circ}$ boundaries increases up to $70^{\circ}$, i.e. a twinning-related boundary is formed. These results are similar to those in Ref. 4). As shown in Fig. 5(b), the decrease of low angle boundaries in $\mathrm{Fe}-\mathrm{N}$ alloys is similar to that in $\mathrm{Fe}-\mathrm{C}$ alloys. The high angle boundary profile in $\mathrm{Fe}-$ 1.65 at $\% \mathrm{~N}$ alloy is similar to that in $\mathrm{Fe}-0.83$ at\% $\mathrm{C}$ alloy, whereas those in $\mathrm{Fe}-2.70$ at $\% \mathrm{~N}$ and $\mathrm{Fe}-1.74$ at\% $\mathrm{C}$ alloys are similar. This profile similarity shows that the fraction of the boundaries in a packet is also affected by nitrogen. The frequency of block boundary occurrence in Fe-N alloys is similar to that in $\mathrm{Fe}-\mathrm{C}$ alloys, although nitrogen is not as effective as carbon in inducing block boundaries.

The difference in the observed dislocation densities is shown in Fig. 6. The dislocation densities in Fe-N alloys are lower than those in $\mathrm{Fe}-\mathrm{C}$ alloys with the same carbon level. ${ }^{15)}$ Furthermore, the average thickness of martensite laths in $\mathrm{Fe}-\mathrm{N}$ alloys is also lower than that in $\mathrm{Fe}-\mathrm{C}$ alloys as shown in Fig. 7.

Figure 8 shows micro Vickers hardness results. We found that the hardness increases with increasing carbon and nitrogen content and that the hardness values are slightly higher in $\mathrm{Fe}-\mathrm{N}$ alloys than in $\mathrm{Fe}-\mathrm{C}$ alloys. However, the different stress conditions of the $\mathrm{Fe}-\mathrm{C}$ (bulk specimens, 

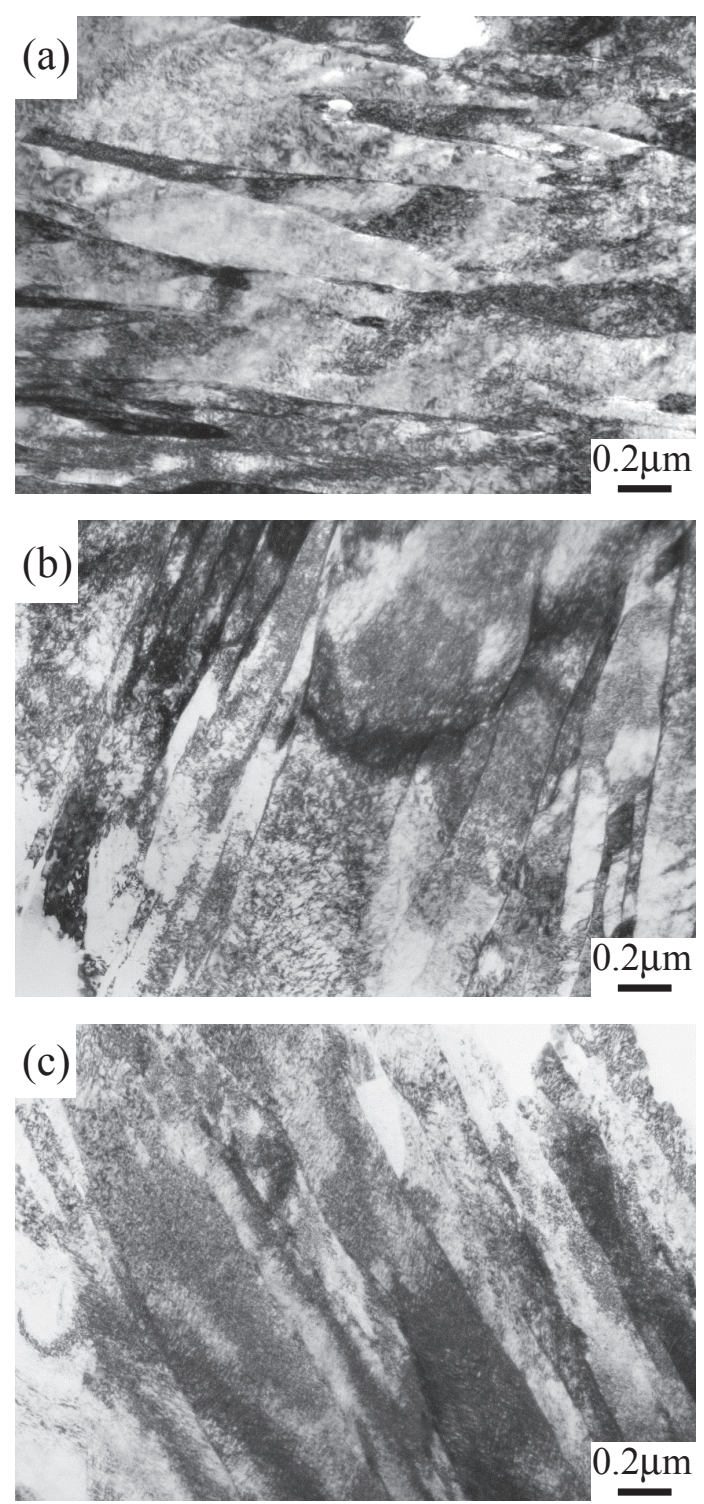

Fig. 3 TEM images of (a) Fe-0.87, (b) 1.65 and (c) 2.70 at\% $\mathrm{N}$ alloys.

Table 1 Microstructural sizes measured using optical microscopy and SEM/EBSD in Fe-N alloys.

\begin{tabular}{cccccc}
\hline $\begin{array}{c}\text { Nitrogen } \\
{[\text { at\%] }}\end{array}$ & {$[$ mass\%] } & $\begin{array}{c}\text { PAG size } \\
{[\mu \mathrm{m}]}\end{array}$ & $\begin{array}{c}\text { Packet size } \\
{[\mu \mathrm{m}]}\end{array}$ & $\begin{array}{c}\text { Block } \\
\text { thickness } \\
{[\mu \mathrm{m}]}\end{array}$ & $\begin{array}{c}\text { Sub-block } \\
\text { thickness } \\
{[\mu \mathrm{m}]}\end{array}$ \\
\hline 0.87 & 0.22 & 392 & 105 & 3.4 & 1.5 \\
1.65 & 0.42 & 286 & 56 & 2.2 & 1.5 \\
2.70 & 0.69 & 533 & 47 & 1.2 & 0.8 \\
\hline
\end{tabular}

Table 2 Microstructural sizes measured using TEM in Fe-N alloys.

\begin{tabular}{cccc}
\hline $\begin{array}{c}\text { Nitrogen } \\
{[\mathrm{at} \%]}\end{array}$ & {$[$ mass\%] } & $\begin{array}{c}\text { Lath } \\
\text { thickness } \\
{[\mu \mathrm{m}]}\end{array}$ & $\begin{array}{c}\text { Dislocation } \\
\text { density } \\
{\left[\mathrm{m}^{-2}\right]}\end{array}$ \\
\hline 0.94 & 0.24 & 0.14 & $7.8 \times 10^{14}$ \\
1.43 & 0.36 & 0.14 & - \\
2.00 & 0.51 & 0.17 & $1.1 \times 10^{15}$ \\
2.60 & 0.67 & 0.24 & $1.5 \times 10^{15}$ \\
\hline
\end{tabular}

Table 3 Microstructural sizes in Fe-C alloys. Microstructural sizes in $\mathrm{Fe}-$ 0.01 at\% C-1.50 at\% Mn were referred from Ref. 11).

\begin{tabular}{ccccccc}
\hline $\begin{array}{c}\text { Carbon } \\
{[\text { at\% }]}\end{array}$ & {$[$ mass\%] } & $\begin{array}{c}\text { PAG size } \\
{[\mu \mathrm{m}]}\end{array}$ & $\begin{array}{c}\text { Packet } \\
\text { size } \\
{[\mu \mathrm{m}]}\end{array}$ & $\begin{array}{c}\text { Block } \\
\text { thickness } \\
{[\mu \mathrm{m}]}\end{array}$ & $\begin{array}{c}\text { Sub-block } \\
\text { thickness } \\
{[\mu \mathrm{m}]}\end{array}$ & $\begin{array}{c}\text { Lath } \\
\text { thickness } \\
{[\mu \mathrm{m}]}\end{array}$ \\
\hline $0.01^{*}$ & 0.0026 & 320 & 130 & 15 & 7 & 0.6 \\
0.83 & 0.18 & 201 & 67 & 7.3 & 2.2 & 0.56 \\
1.74 & 0.38 & 228 & 34 & 1.1 & 0.7 & 0.50 \\
2.77 & 0.61 & 189 & 10 & 0.9 & 0.8 & 0.32 \\
\hline
\end{tabular}

${ }^{*} \mathrm{Fe}-0.01$ at $\% \mathrm{C}-1.50$ at $\% \mathrm{Mn}$.

(a)

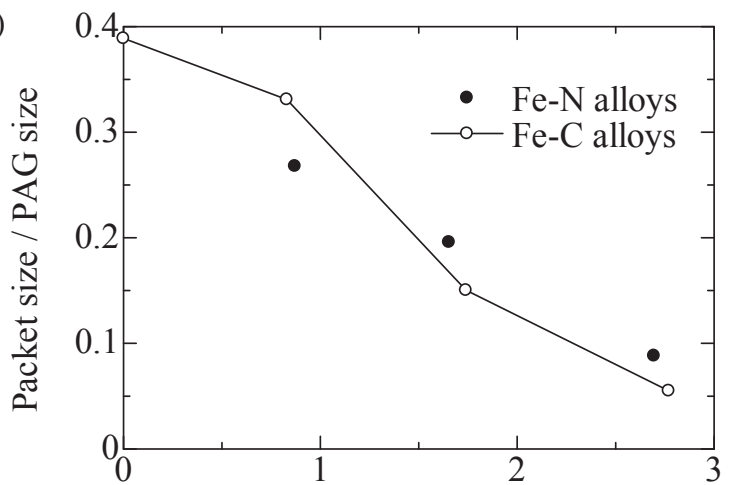

Composition of carbon and nitrogen, at $\%$

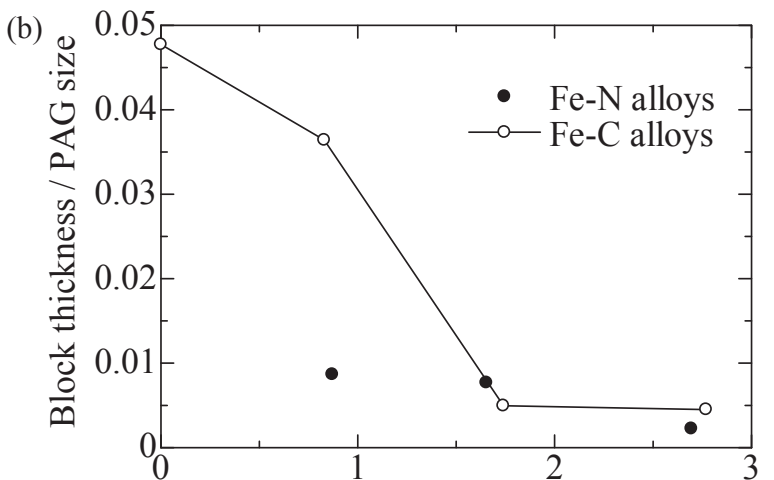

Composition of carbon and nitrogen, at $\%$

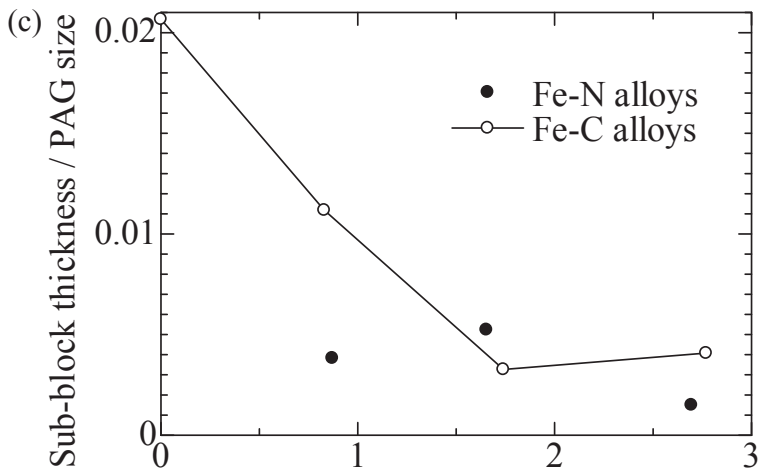

Composition of carbon and nitrogen, at $\%$

Fig. 4 Relationship of microstructural sizes with nitrogen and carbon content: (a) packet size, (b) block and (c) sub-block thicknesses. Size and thickness values are divided by PAG size.

$9.8 \mathrm{~N}$ ) and $\mathrm{Fe}-\mathrm{N}$ (foil specimens, $1.96 \mathrm{~N}$ ) alloys measurements must be taken into account when comparing the hardness results. 

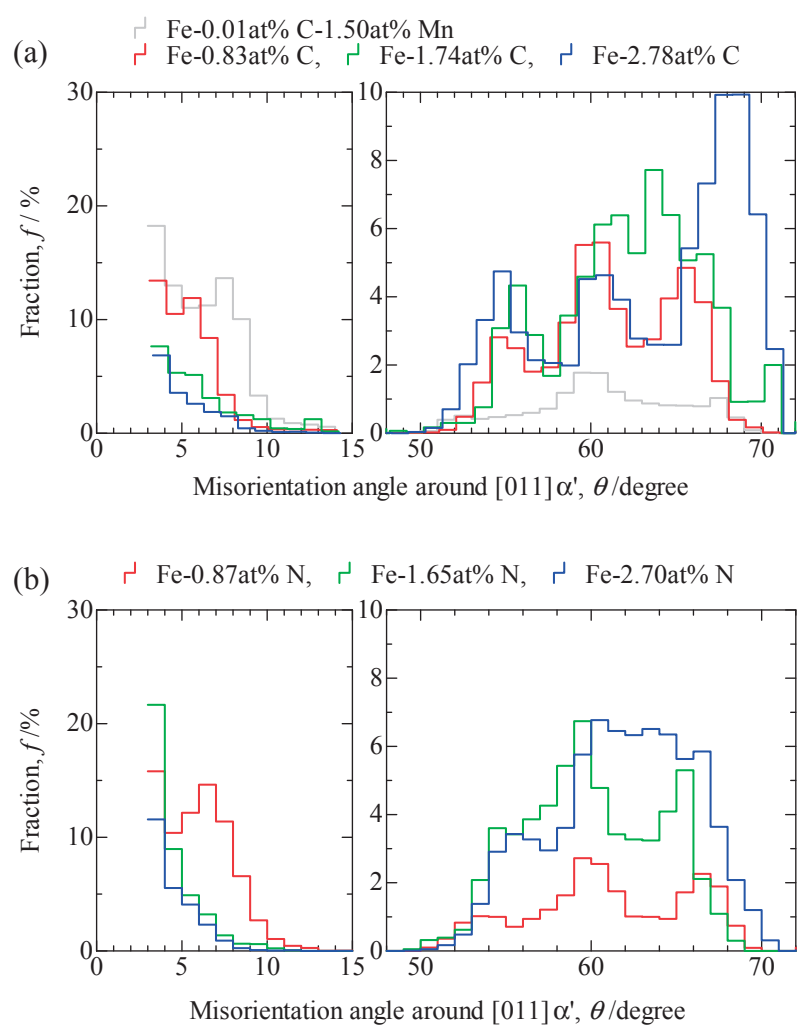

Fig. 5 Fraction of boundaries in a packet plotted against the misorientation angle around the common [011] direction: (a) $\mathrm{Fe}-\mathrm{C}$ and (b) $\mathrm{Fe}-\mathrm{N}$ alloys.

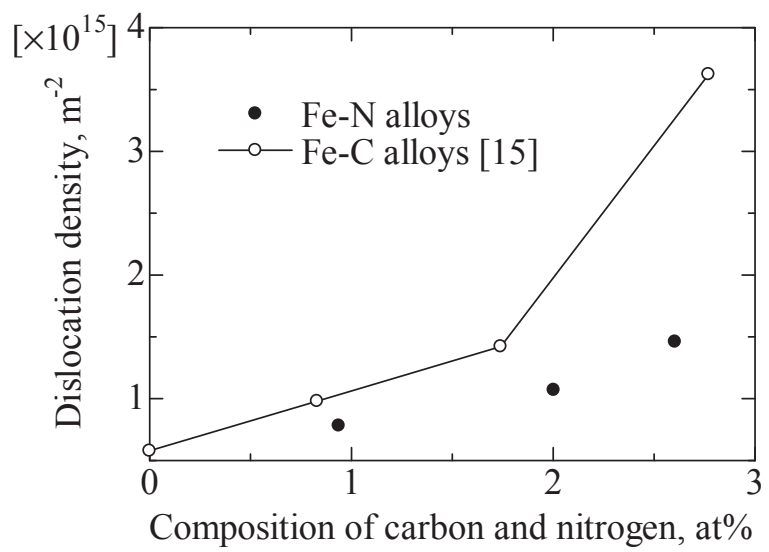

Fig. 6 Dislocation densities in Fe-N and Fe-C alloys. ${ }^{15)}$

To consider the microstructural differences such as block, sub-block and lath thicknesses, it is necessary to discuss the mechanical conditions in the austenite. Solution hardening factor for nitrogen in $\mathrm{Fe}-\mathrm{Ni}-\mathrm{Cr}$ austenitic stainless steels is 2.5 times higher than that for carbon. ${ }^{16)}$ This means that the microstructure growth is suppressed because of the grater effect of nitrogen than carbon on solution hardening. Owing to the difference in hardness, the density of dislocations induced by martensitic transformation is lower in $\mathrm{Fe}-\mathrm{N}$ austenite. Since the dislocations formed in the austenite are inherited into the martensite laths, $\left.{ }^{17}\right)$ the dislocation density in $\mathrm{Fe}-\mathrm{N}$ alloys is lower than that in $\mathrm{Fe}-\mathrm{C}$ alloys.

\section{Conclusions}

The microstructural size, orientation relationship, disloca-

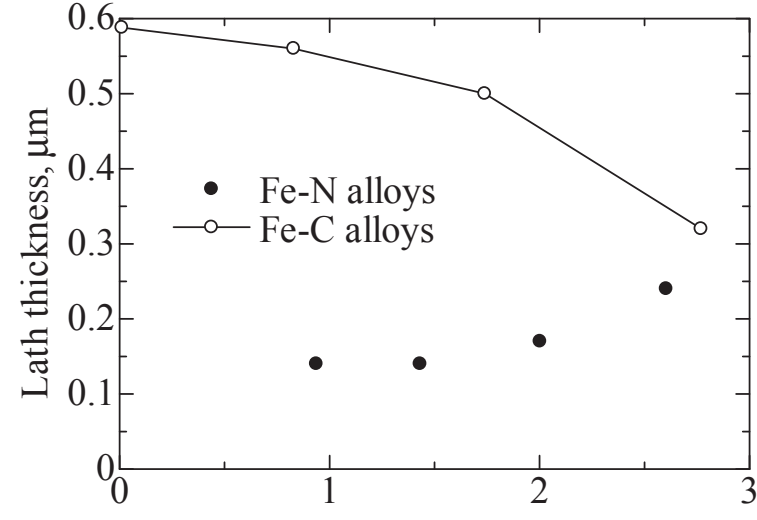

Composition of carbon and nitrogen, at $\%$

Fig. 7 Thickness of martensite laths in $\mathrm{Fe}-\mathrm{N}$ and $\mathrm{Fe}-\mathrm{C}$ alloys.

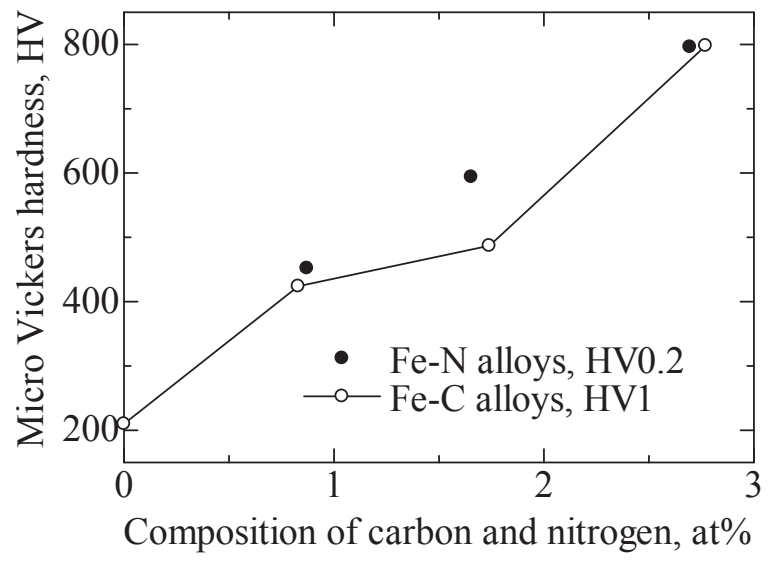

Fig. 8 Micro Vickers hardness in $\mathrm{Fe}-\mathrm{N}$ and $\mathrm{Fe}-\mathrm{C}$ alloys.

tion density and hardness of lath martensite in $\mathrm{Fe}-\mathrm{N}$ alloys containing 0.87 to 2.70 at $\% \mathrm{~N}$ were measured by optical microscopy, SEM/EBSD and TEM. The main results are as follows.

(1) Lath martensite morphology in Fe-N alloys is similar to that in $\mathrm{Fe}-\mathrm{C}$ alloys. The packet/PAG size ratios are similar in $\mathrm{Fe}-\mathrm{C}$ and $\mathrm{Fe}-\mathrm{N}$ alloys with the same carbon and nitrogen content, with the ratios decreasing with increased carbon and nitrogen content. The block and sub-block thicknesses/PAG size ratio in the low nitrogen lath martensite is lower than that in the low carbon lath martensite, although those for the medium and high carbon and nitrogen content are similar.

(2) The fraction of low angle boundaries, i.e. the sub-block boundaries, decreases with increasing nitrogen content, whereas the fraction of the $[011] \alpha^{\prime} / 68^{\circ}$ boundaries increases. The profile of block-boundary frequency in $\mathrm{Fe}-\mathrm{N}$ alloys is similar to that in $\mathrm{Fe}-\mathrm{C}$ alloys, but the fraction is smaller than that with the same carbon level. Effect of nitrogen on the fraction of block-boundary is smaller than that of carbon.

(3) Lath thickness and dislocation density in Fe-N alloys are lower than those in $\mathrm{Fe}-\mathrm{C}$ alloys with the same interstitial concentration. 


\section{Acknowledgment}

The financial support of Research Foundation for Materials Science currently known as Hitachi Metals Materials Science Foundation is gratefully acknowledged.

\section{REFERENCES}

1) A. R. Marder and G. Krauss: Trans. Quarterly 60 (1967) 651-660.

2) T. Inoue, S. Matsuda, Y. Okamura and K. Aoki: Trans. JIM 11 (1970) $36-43$.

3) A. Lambert-Perlade, A. F. Gourgues and A. Pineau: Acta Mater. 52 (2004) 2337-2348.

4) S. Morito, H. Tanaka, R. Konishi, T. Furuhara and T. Maki: Acta Mater. 51 (2003) 1789-1799.

5) T. Bell: J. Iron Steel Inst. 206 (1968) 1017-1021.

6) H. Okamoto (ed.): Phase Diagrams of Binary Iron Alloys, (ASM International, Materials Park, OH, 1993) pp. 222-242.

7) H. K. L. Ngo, K. Nakashima, T. Tsuchiyama and S. Takaki: Tetsu-to-
Hagané 98 (2012) 25-31.

8) M. Ojima, Y. Adachi, Y. Tomota, K. Ikeda, T. Kamiyama and Y. Katada: Mater. Sci. Eng. A 527 (2009) 16-24.

9) P. B. Hirsch, A. Howie, R. B. Nicholson, D. W. Pashley and M. J. Whelan: Electron Microscopy of Thin Crystals, (Krieger Publishing, Malabar, FL, 1977) pp. 422-424.

10) D. B. Williams and C. B. Carter: Transmission Electron Microscopy, (Plenum Publishing, New York, 1996) pp. 321-323.

11) S. Morito, X. Huang, T. Furuhara, T. Maki and N. Hansen: Acta Mater. 54 (2006) 5323-5331.

12) T. Maki, K. Tsuzaki and I. Tamura: Trans. ISIJ 20 (1980) 207-214.

13) S. Morito, H. Yoshida, T. Maki and X. Huang: Mater. Sci. Eng. A 438440 (2006) 237-240.

14) P. M. Kelly, A. Jostsons and R. G. Blake: Acta Metall. Mater. 38 (1990) 1075-1081.

15) S. Morito, J. Nishikawa and T. Maki: ISIJ Int. 43 (2003) 1475-1477.

16) K. J. Irvine, D. T. Llewellyn and F. B. Pickering: J. Iron Steel Inst. 199 (1961) 153-175.

17) A. Shibata, S. Morito, T. Furuhara and T. Maki: Acta Mater. 57 (2009) 483-492. 